\title{
El futuro de los bienes comunales
}

\author{
por \\ RAMON MARTIN MATEO \\ Profesor de la Universidad de Madrid
}

SUMARIO: I. LOS BIENES COMUNALES EN EL MEDIO HISTORICO DE LA VIDA RURAL: 1. Las formas socio-económicas medievales. 2. El sentido primario de los bienes comunales. - II. LAS CONCEPCIONES DEL SIGLO XIX Y SU TRASCENDENCIA PARA LA REgULACIÓN ACTUAL DE LOS BIENES COMUNALES: 1. La racionalización administrativa. 2. El espontaneismo económico.-III. LAS ACTUALES DISFUNCIONES DE LOS BIENES COMUNALES EN EL MUNICIPIO RURAL: 1. La regulación vigente. 2. Desfasamiento ecomómico. 3. Distorsiones sociológicas.-IV. EL FUTURO RÉGIMEN DE LA REFORMA DE LOS BIENES COMUNALES Y LA REVALORIZACION DE LA VIDA RURAL: 1. Trascendencia económica de los bienes comunales. 2. Importancia social. 3. Dificultades de la reforma. 4. Solución que se propugna. 5. Los impulsos complementarios.-V. CONCLUSIONES.

\section{LOS BIENES COMUNALES EN EL MEDIO HISTORICO DE LA VIDA RURAL}

1. LAS FORMAS SOCIO-ECONÓMICAS MEDIEVALES.

Parece innecesario rastrear más profundamente, hacia arriba en la Historia, los momentos anteriores a la aparición conocida de la peculiar forma dominical y de organización productiva que aquí nos interesa. Tampoco aborda la presente exposición la indagación rigurosa de las instituciones jurídicas y políticas que favorecieron la originación de los bienes comunales, máxime después que la decisiva monografía de NIETo (1) ha despejado las principales in-

(1) Vid. su definitiva monografía Bienes comunales, Madrid, 1964. Especialmente páginas 27 y siguientes. 
cógnitas o al menos trazado las líneas magistrales que permiten llegar a la precisión de las distintas vías posibles a lo largo de las cuales se ha desenvuelto en el transcurso de la Historia esta forma de propiedad.

Es más el momento económico-organizativo, el que primero atrae nuestra atención en cuanto que, sean cualesquiera los impulsos externos que favorecieron la aparición de los bienes comunales, su aglutinamiento jurídico-institucional viene intimamente vinculado con las condiciones obrantes en un determinado medio ambiental. Este medio se caracterizaba, desde el ángulo investigatorio aquí abordado, por la existencia de un sustratum económico elemental en el que la organización de la producción resultaba fundamentalmente orientada por los imperativos del autoconsumo y por la limitación de los intercambios de productos, lo que impedía el surgimiento de una economía de mercado al carecerse de los indispensables elementos de transporte y comunicación que exige todo intercambio organizado de bienes.

Las comunidades rurales constituían fundamentalmente islotes básicamente autárquicos en las que los individuos que las componian habían de contar sustancialmente con su propio esfuerzo $\mathrm{y}$ con el apoyo de los restantes individuos del grupo para su sustento y pervivencia (2). Estas comunidades tenian pues, una organización trazada de conformidad a los imperativos de su rudimentaria economía. Sólo lentamente y por la influencia de ideas ajenas, no siempre satisfactoriamente asimiladas, se superpone a la fraternidad espontánea y primitiva de índole defensiva y mutual, una organización jurídico-pública vinculada con formas más amplias y exteriores que acusaban el impacto de las ideas romanas sobre la espontánea estructuración corporativa. Durante el más largo período de su historia el Municipio rural permanece, sin embargo, afincado en los moldes tradicionales que determinaba su áspero medio, dando lugar a formas organizatorias elementales que aún perduran, como veremos, al tratar de los bienes vecinales, pese a

(2) Vid. con base a la trayectoria histórica del Municipio rural germano, pero con trascendencia para otros paises dada la relativa homogeneidad de circunstancias históricas, mi obra El Municipio y el Estado en el Derecho alemán, Madrid, 1965, páginas 17 y siguientes. 
los decididos intentos posteriores de encasillar a todas estas comunidades en marcos uniformes sensiblemente administrativizados.

\section{EL SENTIDO PRIMARIO DE LOS BIENES COMUNALES.}

Dentro del ámbito antes reseñado los bienes comunales aparecen como una pieza indispensable de la originaria organización socio-económica de la vida rural. No puede ser casual el que en todos los países occidentales, en su etapa feudal, los bienes comunales constituyan un denominador común en las colectividades agrarias. Es por ello por lo que, aunque pueda admitirse de buena gana la existencia de impulsos múltiples y dispares que concurrieron a su estructuración, todos ellos abocan en definitiva a los mismos resultados porque no se trataba de originar artificialmente una institución, sino de servir a las exigencias elementales de la vida económica en las épocas en que se detecta la aparición de estos patrimonios colectivos (3).

Los bienes comunales representaban así una masa común de bienes que, de una parte, posibilitaba el aglutinamiento del grupo facilitando su integración $y$, de otra, suministraba un imprescindible complemento para las explotaciones agrícolas monofamiliares, base principal de estas economías. En estas primarias

(3) De acuerdo con Vicens Vices, Historia económica de España, 3." edicíon, Barcelona, 1964, página 123, para este período lo mejor es adoptar el término de economía vecinal, «pues resume una especie de autarquia de aldea, más o menos vinculada a otras aldeas por un rudimentario mercado. En la Meseta, un tipo ideal es el que esquematizamos a continuación. El centro de la vida económica es el vicus, o sea, la aldea. Comprende dos clases de propiedades: individuales y colectivas. La parte individual, llamada fundus o hereditas, está centrada por la casa'(domus), que algunas veces se denomina fumus (del humo que sale de la chimenea de esta casa). Una explotación agrícola estable necesita, por lo menos, cuatro piezas: la terra o serna, donde se cultivan los cereales; la ferregenalia, o sea, la tierra donde se cultiva el forraje para el ganado; el huerto (hortus), y la curtes, o lugar donde se reúne el ganado. En cuanto a la explotación colectiva, en general las tierras no eran propiedad de la aldea, sino del rey o del señor, y por ellas la aldea pagaba un tributo. Se dedicaban a los siguientes usos: la defesa, o sea, la dehesa, donde pastaban los bovinos; el cotus, bosque donde se cazaba; la mesta (nombre que alcanzó importancia extraordinaria en la vida económica castellana), donde se llevaba a apacentar los rebaños de corderos, y, finalmente, la piscaria, o sea, lagos y ríos, donde el aprovechamiento de la pesca era colectivo. 
agrupaciones rurales, cerradas sobre sí mismas, los individuos que las componían precisaban de una reserva productiva colectiva para atender necesidades no susceptibles de aislado atendimiento. En ella podían los agricultores medievales encontrar elementos indispensables para su vida cotidiana sobre los que una apropiación individual era no sólo impensable, sino también rigurosamente inviable. Pero, además, la inexistencia de empresas agrícolas en el sentido moderno sólo podía ser paliada por la fórmula colectiva a que los bienes comunales responden, que sustituía otras modalidades más complejas de agrupación de esfuerzos. Vemos, pues, que estos bienes constituyen una natural respuesta a los condicionamientos ambientales de un determinado medio histórico y fundamentalmente a la ausencia de mercados organizados, la indiferenciación de los esfuerzos productivos, la autarquía económica y el aislamiento de las colectividades rurales. Es por ello por lo que parece conveniente repensar su configuración legal en el momento actual, máxime si como más adelante se expone han sufrido posteriormente el impacto desnaturalizador no sólo de las nuevas estructuras económicas, sino también de otras ideas que dogmáticamente se les superpone como consecuencia de trastocamientos de origen dogmático del orden político y administrativo.

\section{LAS CONCEPCIONES DEL SIGLO XIX Y SU TRASCEN- DENCIA PARA LA REGULACION ACTUAL DE LOS BIENES COMUNALES}

\section{LA RACIONALIZACIÓN ADMINISTRATIVA.}

Los bienes comunales, como vimos, encuentran su clima adecuado en una organización, fundamentalmente económica, de las colectividades rurales en cuanto que facilitan a sus miembros la utilización de los recursos naturales a su alcance, de acuerdo con técnicas simples y elementales de producción. La influencia de las ideas providencialistas de la Ilustración, que encontraron amplia tribuna y extrema difusión en la Revolución francesa, impusieron una conformación racionalista de la organización comunitaria, 
administrativizando las colectividades espontáneas y encajándolas en fórmulas uniformes organizatorias a partir de un trazado más o menos geométrico de distribución de los límites territoriales de las competencias.

Surge así el Municipio moderno con pretensiones de exclusividad y monopolio, ideas éstas definitivamente afianzadas, también en nuestro país, a partir de las Cortes de Cádiz. Estas concepciones venían, como es sabido, basadas en la noción de la omnipotencia de la soberanía popular cuyo poder no debería encontrar barreras ni obstáculos todo a lo ancho del territorio de la Nación, centralmente gobernada por los representantes populares. Ello conducía naturalmente a la politización y administrativización de todas las comunidades de base territorial encajadas en la fórmula ayuntamentista, propendiéndose a desconocer tanto la existencia de otras colectividades espontáneas que por sus reducidos efectivos no fuesen idóneas para estas soluciones, como los últimos fundamentos económicos de estas modalidades de convivencia y las preocupaciones productivas del campesinado. Para estos problemas se ofrecían técnicas distintas, como las de fomento, regidas y manejadas desde el centro por los depositarios del poder popular animados de las ideas de la sabiduría ilustrada.

\section{El ESPONTANEISMO ECONÓMICO.}

Curiosamente, sin embargo, en el ideario novecentista se incluyen, para el campo económico, concepciones en alguna manera antagónicas a las que hicieron cristalizar la racionalización de la organización administrativa. Aquí aparece el límite de lo administrativizado en cuanto que se propende a liquidar toda clase de obstáculos que coarten el libre e individualista desenvolvimiento de las fuerzas económicas. No sólo las trabas y barreras entroncables con el mundo feudal van a ser eliminadas, sino también cualquier clase de coartamientos colectivos al tipo de expansión económica de base individual que se juzgaba el más idóneo.

Estas tendencias favorecieron, por un lado, la atomización de la propiedad rural a través de las vías jurídicas sancionadas por 
el Código civil, y, por otro, tendieron a la movilización de los patrimonios colectivos por medio de la desamortización. La magna obra desamortizadora sobre cuyo indudable acierto, pero lamentable instrumentación, no vamos a insistir aquí, respondía a unas tendencias de conjunto loables, pero que, injustificada e innecesariamente, se mostraron enemigas de la patrimonialización de los pueblos y del mantenimiento de sus bienes comunales, con olvido de que estos bienes no constituían un vestigio de fórmulas políticas feudales, sino que representaban una modalidad de organización de la producción agrícola susceptible de ser atemperada a las nuevas corrientes que, reanimadoras, pretendían impulsar la vida económica.

Aunque los bienes comunales lograron, institucionalmente al menos, capear estos temporales recurriéndose incluso a su recreación a través de fórmulas evasoras de los rigores de la legislación desamortizadora patentizándose así una vez más su vitalidad y su precisión para el equilibrio económico de la producción agrícola, ello fue a costa de la esclerosificación del sistema, perdiéndose la oportunidad de su revisión y adaptación a las mutaciones socio-económicas. Pero el clima les era hostil y sólo escamoteando su presencia y disminuyendo su importancia pudieron pasar tales pruebas a costa de desvincularse así de la marcha de los tiempos.

Este proceso afectó incluso a las propias condiciones existenciales del Municipio rural, que bajo la artificiosa cáscara politicoadministrativa que le fue impuesto perdió el pulso de la vida económica del grupo, distanciándose del mismo y vaciándose de su más necesaria y vital savia. Donde no había nada apenas que administrar carecía de sentido un aparato ambicioso que ilógicamente volvía la espalda a las preocupaciones mạ́s sentidas de la colectividad que pretendía servir. 


\section{LAS ACTUALES DISFUNCIONES DE LOS BIENES COMUNALES EN EL MUNICIPIO RURAL}

\section{LA REGULACIÓN VIGENTE.}

Prescindiendo de otros aspectos que sólo indirectamente aquí nos interesan, conviene exponer los rasgos fundamentales que para la organización de los aprovechamientos establece nuestra legislación local. De acuerdo con el artículo 192 de la Ley de Régimen local, el disfrute de los bienes comunales habrá de realizarse de conformidad a las siguientes fórmulas de orden prevalente y sustitutorio:

1. En régimen de explotación colectiva o comunal cuando tal disfrute sea practicable.

2.- En caso contrario, según las modalidades de la costumbre o reglamentación local.

3. - Si no existieren prácticas consuetudinarias, mediante adjudicación de lotes o suertes a los vecinos cabeza de familia en proporción directa al número de familiares que tengan a su _cargo e inversa de su situación económica.

4. Sólo si fueran imposibles la utilización de las formas de aprovechamiento anteriormente reseñadas, cada una de las cuales prima sobre las siguientes, podrá autorizarse por el Gobernador civil la adjudicación del disfrute y aprovechamiento en pública subasta, mediante precio, prefiriéndose en igualdad de condiciones a los postores vecinos sobre los forasteros. Ahora bien, en este último caso, de acuerdo con el artículo 81 del Reglamento de Bienes, el producto se destinará a servicios en utilidad de los que tuvieren derecho al aprovechamiento, sin que pueda detraerse por la Corporación más de un 5 por 100 de su importe (4).

(4) El artículo 159 del Estatuto municipal de 1924 disponía igualmente que mientras fuese practicable este modo de disfrute continuarian los aprovechamientos gratuitos por el común de los vecinos y únicamente se enajenarian por precio los productos cuya utilización comunal no resultara posible. 


\section{Desfasamiento económinco.}

El criterio a que responde la anterior regulación continúa anclado en presupuestos propios de épocas ya superadas en las que la organización económica y productiva presentaba el tramado elemental al que ya nos hemos referido. Estas formas de aprovechamiento están pensadas desde una perspectiva de economía de autoconsumo no monetarizada, autárquica y escasamente sometida a los dictados de amplios mercados. Como ha puesto de relieve NiETo (5), por el contrario «la agricultura moderna se ha convertido en una agricultura de mercado, mientras que los bienes comunales siguen orientados por la fórmula tradicional del autoconsumo que se encuentra sancionada, además, por la inercia legislativa».

El Ayuntamiento convertido en un aparato de poder y desvinculado del proceso económico del grupo que representa, nada puede hacer para salir de tal situación con apoyo en la legislación reseñada. De esta forma los bienes comunales quedan al margen del poderoso movimiento que ha impulsado la aparición de la empresa agrícola y que ha sido puesto de relieve entre nosotros por BALLARín (6).

Los bienes comunales faltos de la necesaria capitalización, imprescindible para la organización empresarial de la producción y şin que el carácter antimonetario de sus aprovechamientos ofrezca alternativas utilizables, permanecen sumidos en un letargo secular, improductivos en buena parte, presa fácil de usurpaciones y rapiñas, cuando no radicalmente transformados, en esencia, en bienes patrimoniales del Municipio y utilizados para financiar menguadas empresas administrativas.

El proceso de racionalización de la producción agraria ha orillado los bienes comunales, impidiendo, salvo excepciones, la obtención a través de los mismos de apreciables y generalizados rendimientos, ciertamente para los Ayuntamientos en cuanto que son responsables del atendimiento de las necesidades colectivas,

(5) Bienes comunales, página 909.

(6) Derecho agrario, Madrid, 1965. 
pero también para los propios vecindarios que lógicamente no pueden obtener aisladamente beneficios apreciables y que son, en consecuencia, forzados quizá a abandonar sus ambientes tradicionales, dejando posiblemente a su espalda fuentes de recursos aún inestrenadas.

\section{Distorsiones SOCIOLÓGicas.}

Sería a la vez ingenuo e injusto ver en la actual configuración legal de los bienes comunales la causa principal de los males que afligen al campo español; ahora bien, aunque ello sea una solución parcial y no milagrera, sí cabe esperar de un nuevo tratamiento legal de los mismos alguna ayuda, allí donde ésta sea posible de obtener por estos medios, para la coadyuvación al logro de mejores resultados.

Con tales restricciones y reservas pueden señalarse algunas consecuencias negativas, desde el plano social, del actual planteamiento del Municipio rural, de los bienes comunales en relación con su deseable encuadramiento colectivo.

También por NiETo (7) se ha señalado, en una de sus aportaciones a las Jornadas de Peñíscola, cómo las peculiaridades del Municipio rural pueden ser descritas en síntesis en el sentido de que «en ellos los intereses de índole rural y agrícola predominan sobre los intereses comunitarios ciudadanos, urbanos, propios de los demás Municipios» (8). El legislador liberal del siglo xIx, añade este autor, hizo, sin embargo, al Municipio más un instrumento político que un ente de gestión económica. Siguiendo esta línea argumental es fácil comprender el que las colectividades rurales se hayan despegado de sus órganos gestores, a la larga fatal para la propia integración sociológica del grupo y sin que ello venga paliado por la creación paralela de organizaciones exclusivamente profesionales, fácil polo de atracción de disiden-

(7) «Ayuntamientos y Hermandades sindicales en los Municipios rurales», en Problemas politicos de la Vida local, vol. V, 1965.

(8) «Ayuntamientos y Hermandades...», loc. cit., pág. 158. 
cias y antagonismos indeseables en el seno de comunidades reducidas en las que sería preferible ver una organización única que fundiese todos los intereses, incluidos los de carácter agrícola-económico que aquí, además, son los predominantes.

De otro lado, es de observar que la ausencia de fórmulas colectivas ágiles y actuales en el disfrute y aprovechamiento de los bienes comunales impide contrarrestar las tendencias individualistas perseguidas por la legislación atomizadora que trae su causa del pasado siglo, que tanto han erosionado el sentido comunitario y que hoy, de rechazo, minan las más deseables posibilidades agrupatorias de la organización de nuestra economía agrícola.

Otro factor que desde esta perspectiva debe tomarse en consideración es la existencia de un subgrupo de bienes comunales que se califican como bienes vecinales. Estos bienes pertenecen a comunidades que han quedado al margen del proceso municipalizador y carecen, por tanto, de personalidad jurídica pública, bien que alguna jurisprudencia reciente las asigne una curiosa personalidad jurídica menor precisamente para la administración de estos bienes (9). Los bienes vecinales representan pues, una pervivencia pura de las modalidades comunitarias dominicales de las épocas más antiguas. Sin embargo, su situación actual al no encontrar encaje dentro del encasillado uniformista de nuestra Administración local, resulta adicionalmente problemática, creando graves problemas, tanto en cuanto a su aprovechamiento como en relación con las graves tensiones sociales que se originan entre estas comunidades, los Municipios en cuyos términos están enclavadas, y los propios órganos de fomento de la Administración central que desean acudir en su ayuda.

Por último, debe señalarse que un futuro remodelado del marco jurídico de los bienes comunales y vecinales debería eliminar los inconvenientes que de su actual status se deducen para una revisión racional y ordenada de la organización productiva que im-

(9) Vid. RODRiguez MORo: «Los pueblos no constituidos en Entidad local menor pueden tener el aprovechamiento exclusivo de bienes del común de los vecinos», en REvisTA DE ESTUdios DE LA VIDA LOCAL, número 132, 1963, páginas 467 y siguientes. 
piden la potenciación quizás de la riqueza económica de una zona por el aferramiento de grupos vecinales residuales a los menguados beneficios que obtienen a través de fórmulas tradicionales, pero irracionales, de explotación.

\section{EL FUTURO REGIMEN DE LA REFORMA DE LOS BIE- NES COMUNALES Y LA REVALORIZACION DE LA VIDA RURAL}

1. TRascendencia económica de los bienes comunales.

No es fácil evaluar cuantitativamente cuál sea la cifra de hectáreas que hoy comprenden los bienes comunales, ni mucho menos apreciar cualitativamente sus posibilidades de rendimiento una vez explotados de acuerdo con fórmulas racionales. En todo caso sí puede aventurarse que pese a las sucesivas mermas que estos patrimonios han sufrido a lo largo de los siglos, al abandono de los mismos y la ausencia de inversiones, todavía representan una riqueza de gran consideración que conviene urgentemente sacar de su letargo y de la auténtica hibernación a que por lo general está sometida.

A título meramente orientador pueden darse los siguientes datos: De acuerdo con la Reseña geográfica y estadística de España de 1888 , los montes comunales ascendían a 4.800 .000 hectáreas. En 1896 el Ministerio de Hacienda daba una cifra aproximada de 4.100.000. Con más inmediación el Informe sobre el desarrollo económico de España del Banco Internacional de Reconstrucción y Fomento cifraba en 7.900 .000 las hectáreas ocupadas por los bienes comunales, cifra ésta a la que se aproximaba la Dirección General de Montes cifrando la extensión en 8.085.000, bien que incluyendo todos los bienes municipales y no sólo los de carácter comunal (10).

En cuanto a los bienes vecinales únicamente se disponen los

(10) Datos que tomo de Nieto: Bienes comunales, pág. 871. 
datos contenidos en el Informe presentado por la Subcomisión 5. ${ }^{\mathrm{a}}$ de la 2. ${ }^{\text {a }}$ Comisión al Consejo Económico-Sindical del Noroeste (11), que calcula en 630.000 hectáreas la extensión de este tipo de propiedad para la región gallega, destacándose cómo precisamente la deficiencia de su actual regulación legal no solamente frena la repoblación de estos terrenos que por sus condiciones edafológicas y ambientales se consideran propicios para la forestización, sino que amenaza el futuro de los terrenos ya repoblados, siendo fuente de importantes conflictos tanto a la hora de precisar las bases de estas operaciones como en el momento de proceder al reparto de los beneficios obtenidos. He aquí, pues, cómo encontramos corroborada la tesis, que viene siendo sostenida a lo largo del presente trabajo, de la precisión de revisar con un sentido actual y realista el vigente estatuto de la propiedad comunal si se quiere obtener de ella los rendimientos que tanto para la colectividad nacional como para los grupos comunales afectados es presumible y esperable obtener.

\section{IMPORTANCIA SOCLAL.}

La propiedad comunal, ha dicho con justeza Garrido FALLA (12), «constituye una fórmula intermedia cuyo carácter ejemplar debe ser subrayado en un mundo que se agita en la tensión entre individualismo y colectivismo. En este sentido, y esto no debe olvidarse, es una fórmula llena de sugerencias». Conviene, pues, extraer las aún inéditas posibilidades ínsitas en esta fórmula, no por supuesto en el sentido de mantener a ultranza su actual versión, sino de revisarla acomodándola a las exigencias coetáneas. Los bienes comunales pueden constituir no sólo una importante fuente adicional de recursos para las colectividades rurales, sino también un señalado centro de integración ccmunitaria. En torno a los bienes comunales puede intentarse el lan-

(11) Santiago de Compostela, 1964.

(12) «Sobre los bienes comunales», en REvista dE ESTUdios DE LA VIDA LOCAL, número 125, página 692. 
zamiento de operaciones que tiendan a revalorizar las condiciones de la vida rural, evitando que la transferencia de efectivos humanos vaya más allá del transvase de los excedentes determinados por la sana y deseable mecanización y perfección de los mecanismos agrícolas productivos.

Adecuadamente manejados pueden servir allí donde existan, de estímulo para experiencias de explotación colectiva que vinculen a los campesinos al medio rural haciéndoles experimentar las ventajas del concurso de esfuerzos y de la interdependencia de actividades. Aunque no sea exhaustiva ni pueda lógicamente aislarse, una importante reforma agrícola y social puede intentarse con auxilio de esta tradicional fórmula comunitaria, pues es más fácil partir ya de lo tradicionalmente colectivo que operar radicales innovaciones estructurales. Los bienes comunales una vez sensibilizados a las vigentes condiciones podrán tener un importante efecto ejemplificador, y demostrarán, una vez más, que la presencia de la explotación agrícola colectiva en alguna medida constituye una constante exigencia histórica.

\section{Dificultades de la REForima.}

Debe contarse, sin embargo, con no desdeñables obstáculos para la implantación de sustanciales alteraciones en el vigente régimen de utilización de la propiedad comunal. En primer lugar, y por supuesto, pesarán considerablemente los impulsos de inercia que tienden siempre a contrarrestar todo movimiento reformador. Los hábitos individualistas adquiridos por los habitantes del medio rural como consecuencia del mundo de ideas a que responde el Código civil, son también un factor de consideración que ha obstaculizado largamente los intentos de establecimiento de fórmulas de agricultura de grupo (13).

Pero además deben tenerse en cuenta los conflictos de inte-

(13) Vid. una interesante muestra de estas dificultades en el meritorio trabajo de investigación sociológica realizado por SIGUÁN: El medio rural castellano y sus posibilidades de ordenacion, Madrid, 1966, especialmente páginas 199 y siguientes. 
reses que hoy laten en torno del aprovechamiento de estos bienes y que adquirirán una particular virulencia cuando deban ser quizá contrastados decididamente antes de la adopción de una nueva solución. No debe olvidarse que existen auténticos derechos a los aprovechamientos por parte de los vecindarios, cuyos titulares se resistirán a su pérdida o transformación pese a que sus actuales contenidos económicos sean escasos o puramente virtuales e hipotéticos. La pérdida inmediata del derecho al pastoreo, por ejemplo, a cambio de los más remotos beneficios de una explotación forestal, exigirá determinadas compensaciones y liberará posiblemente mano de obra rural con los consiguientes sacrificios, aunque ello suponga quizás a la larga una mejora para los afectados si se encuentran en auténticas condiciones de perenne subempleo no paliada por los escasos rendimientos de los bienes comunales adicionales a explotaciones individuales deficitarias.

$\mathrm{Ha}$ de sopesarse también el antagonismo, unas veces latente y otras netamente acusado, existente en muchos casos entre comunidades titulares de bienes, sean éstas Entidades locales menores o meros grupos vecinales, y comunidades más amplias o simplemente de más peso administrativo por radicar en ellas el Ayuntamiento, que aspiran a obtener una porción de los beneficios obtenibles de aquellos bienes. Lo mismo puede decirse, desde otra perspectiva, de las aspiraciones, hasta cierta medida legítimas, de los Ayuntamientos a aplicar los rendimientos de los bienes comunales a la financiación de los servicios por ellos atendidos.

\section{SOLUCIÓN QUE SE PROPUGNA.}

Al hilo de la exposición aquí contenida es fácil posiblemente anticipar cuáles vayan a ser las soluciones que para el problema actual de los bienes comunales y de los propios Municipios rurales en que están enmarcados se sugieran. Se solicita en efecto un retorno al auténtico sentido de explotación colectiva que estos bienes tuvieron en las épocas históricas que determinaron su aparición, sentido éste que no implica el mantenimiento de sus vigentes modalidades de disfrute en cuanto que constituyen, por el 
peso de otras nuevas circunstancias, una contradicción patente a los imperativos de su propio destino. Se impone, por el contrario, la corrección de este desfasamiento con recurso cuando sea posible a fórmulas sustitutivas del anterior espontáneo concurso de los hombres del campo: me refiero a las fórmulas de agricultura de grupo que hoy están siendo ensayadas con mayor o menor fortuna, pero que parecen sin duda tener ante sí un ancho y prometedor futuro. En este sentido se ha señalado acertadamente por BAZ IZqUIERDo que: «Con referencia, en concreto, a los bienes comunales, cabe afirmar que el ejemplo de la asociación de agricultores en Cooperativas, Grupos sindicales y otras formas de explotación en común debe inducir a los Ayuntamientos a estudiar la ordenación de aquéllos siguiendo técnicas más acordes con nuestro tiempo, teniendo presente que una de las consecuencias inmediatas de la reforma agraria debe ser la de llevar nueva vida comunitaria y nueva riqueza de nuestros entes locales, flexibilizando y dotando de la necesaria capacidad de adaptación a sus estructuras administrativas y sociales» (14).

Tal solución viene a la vez determinada por el peso de otro factor decisivo: el surgimiento de la empresa cuya adaptación al medio rural constituye un imperativo imprescindible y que puede encontrar acomodo perfectamente dentro de la fórmula cooperativa. Sólo mediante una gestión empresarial de los bienes comunales podrá obtenerse el rendimiento esperable de tales patrimonios, facilitándose la afluencia de los capitales que cada día con mayor intensidad exigen las explotaciones agrarias modernas (15).

(14) BAZ IzquIERDo: «Explotación colectiva de los bienes comunales de aprovechamiento agrícola», en Revista de Estudios Agro-sociales, número 51, 1965, página 35 .

(15) Aunque ello no guarde de momento parangon con las condiciones de este pais puede ser aleccionador el ejemplo de los actuales caracteres de la economía agraria en una Nación extremadamente desarrollada como Norteamérica. En este país se ha tomado a conciencia de que uno de los aspectos más interesantes de la evolución actual es la interdependencia entre la agricultura y su contexto, dando lugar al denominado agri-business, sector que engloba 24 millones de personas activas, de las cuales cinco trabajan en la tierra, once en la industria agrícola y ocho en el sector terciario, entre todas las cuales se aprecia un cierto sentimiento de solidaridad. 
El sustratum colectivo que la agricultura de grupo suministra compatibilizaría así la armonización de las técnicas empresariales con la vocación comunitaria de los bienes analizados (16).

Para facilitar esta transformación y a la par restañar los cortes que se han venido produciendo entre los componentes de las comunidades rurales y su organización administrativa, se juzga aconsejable revitalizar la dimensión económica de los Ayuntamientos en las pequeñas colectividades donde los intereses son integramente profesionales agrícolas y donde no cabe, por tanto, una organización que no tenga como misión fundamental su atendimiento. Ello no quiere decir que la gestión técnica requerida para la explotación de los bienes comunales de acuerdo con las nuevas fórmulas de agricultura de grupo propuestas, haya de ser efectuada con los mismos mecanismos que hoy integran la Administración municipal, pero sí que entre Ayuntamientos y cooperativas de bienes comunales o cooperativas de término municipal debe existir una interconexión suficiente para eliminar toda clase de antagonismos y toda posibilidad de fricción entre centros económicos y administrativos de poder. Creemos con BaLLaRín que los aprovechamientos colectivos serán mucho más seguros si se saben apoyar sobre la infraestructura municipal (17), lo que a la par solucionará en otros aspectos importantes problemas como los de la garantización de los créditos necesarios para la financiación de las requeridas inversiones.

La explotación de los bienes comunales podrá constituir así un centro aglutinador de esfuerzos y una plataforma desde la que podrán lanzarse más ambiciosas operaciones colectivas. Tal transformación supondrá posiblemente el sacrificio inmediato de algu-

(16) «La agricultura de grupo, señala GARCía DE OTEYZA, pretende, no sólo una concentración de capitales, sino una verđadera agrupación de hombres. Las fórmulas asociativas tienen que proporcionar al campo, además de una fusión de intereses, una fuerte cohesión social». Prólogo a la obra de BuEno GOMEZ, J. LAMO DE EsPinOSA y BAZ IZquIERdo, Explotación en común de la tierra y concentración parcelaria, Madrid, 1966, página 9.

(17) Vid. su estudio «Nuevas fórmulas asociativas para la agricultura», en Las asociaciones profesionales agrarias y la agricultura de grupo, etcétera. Servicio Nacional de Concentración Parcelaria y Ordenación Rural. Madrid, 1964, página 38. 
nos derechos y la realización de una adecuada composición de intereses (18). Los titulares de los aprovechamientos que no puedan seguir realizándolos por no participar en la explotación colectiva habrian de ser indemnizados capitalizándose los perjuicios que se les irrogue. Los que activamente realicen su explotación habrán de percibir los beneficios imputables a su gestión (19), asignándose a los entes de carácter municipal una cuota idónea para el atendimiento de las necesidades colectivas. En cuanto a los bienes de carácter vecinal se juzga imprescindible el reconocimiento de su actual situación (20), permitiéndose la explotación de sus bienes. en forma similar a la propugnada para los bienes comunales típicos sin perjuicio de que también colaboren a los gastos de la organización municipal que les comprende. Por último, no debe descartarse la posibilidad de que el aprovechamiento de todos $\epsilon$ stos bienes no permita su colectiva explotación por tratarse de superficies idóneas, por ejemplo, para su forestización, como es el caso de la región gallega (21), pero aun en tales supuestos debe enérgicamente descartarse el que el mantenimiento de las modalidades tradicionales de utilización impida su racional explotación con perjuicio de más fundamentales intereses. En estos casos habrán, también, posiblemente, de arbitrarse fórmulas de transición y de compensación por los beneficios inmediatamente perdidos. Parecidas

(18) En la línea acertadamente sugerida por la Comisión del Consejo Económico Sindical Interprovincial del Noroeste a que nos hemos referido, páginas 78 y siguientes de su Informe.

(19) Debe convenirse con BAZ Izquiendo que parece aconsejable la derogación del artículo 31 del Reglamento de Bienes que imposibilita el que los rendimientos económicos de las explotaciones de los bienes comunales puedan ser distribuidos en metálico entre quienes contribuyan personalmente a la obtención de los rendimientos. Sin ello, de acuerdo igualmente con este autor, no cabe esperar el suministro de los incentivos necesarios para una mejora de los rendimientos y una dedicación intensa y personal a su potenciación. «Explotación colectiva de los bienes comunales...», cit. páginas 64 y 65 .

(20) Con apreciable realismo se dice en el Informe de la Comisión del Consejo Sindical citado que hay que empezar por afirmar el reconocimiento de que «esa entidad pueblo, lugar o parroquia existe», página 77 .

(21) Vid. el Informe anteriormente citado, donde se pone de relieve las grandes posibilidades en este sentido de la región, que vienen en la actualidad negativamente afectadas en buena parte precisamente por el deficiente estatuto obligado de sus bienes colectivos. 
soluciones podrian mediar cuando resulte aconsejable la reagrupación de poblaciones como consecuencia de los dictados de la reordenación territorial.

Es claro que la implantación de las indicadas reformas va más allá de una mera revisión del régimen de los bienes comunales, implicando una auténtica reestructuración de la organización del medio rural. Pero como señala E. LAMO DE EsPINOSA, «se impone acelerar, pero también matizar, el proceso de reforma de nuestras estructuras agrarias y con ello, paralela y sincronizadamente, poner al día nuestra Administración local, caduca y desfasada en muchas de sus concepciones» (22). Las peculiares condiciones del Municipio rural exigen su mayor identificación con las preocupaciones fundamentales de sus vecindarios, que a diferencia de lo que sucede con el Municipio urbano tienen un denominador común y deben estar representadas y atendidas desde su organización administrativa. Las necesidades propiamente urbanas y la dotación y mantenimiento de los servicios que deban facilitarse a los habitantes del medio habrían de afrontarse quizá en mayor proporción con un planteamiento más amplio y comarcal (23) que permita el acceso de los habitantes del sector agrícola a las facilidades y beneficios ofrecidos por la civilización de nuestros días.

\section{LOS IMPULSOS COMPLEMENTARIOS.}

Ha de descartarse que las transformaciones que aquí aparecen como deseables puedan realizarse simplistamente mediante una mera revisión legislativa. La modificación de la normativa vigente tan sólo suministrará la indispensable apoyatura del sistema y el punto de partida para la obra a realizar. El resto vendrá posiblemente en buena medida favorecido por las mutaciones de las condiciones de nuestra economía que a la larga arrastrarán a tales

(22) «La Administración local y la política agraria», en Revista de Estudios Agro-sociales, número 44, 1963, página 31.

(23) Vid. mi estudio La comarcalización de los pequeños Municipios, Madrid, 1964, y SIGUÁN: El medio rural castellano y sus posibilidades de ordenación, quien se muestra inclinado a un desarrollo comarcal suficientemente planeado y ordenado como solución óptima para la promoción del campo. 
transformaciones, si es que no se favorece imprudentemente la cristalización definida de las actuales estructuras con medidas aparentemente de carácter benefactor, pero intrínsecamente, y a la larga, regresivas (24).

Pero si este proceso ha de ser adecuadamente encauzado y estimulado deberá contarse con el concurso de los Servicios de la Administración que ya vienen actuando tan destacadamente en el medio rural donde han ganado una ejemplar ejecutoria. Sólo así, en inmediación con los problemas y en contacto directo con los afectados por los mismos, podrán vencerse las pesadas inercias.

(24) Vid. VALARche: Economía agraria, trad. esp., Madrid, 1961, y, sobre todo, Rivero: «A propos des metamorphoses de l'Administration d'aujourd'hui», en Mélanges cfferts a René Savatier, París, 1965, página 833 , donde se señala el surgimiento del vigoroso movimiento que se puede llamar «joven campesino». «Para comprender esto, añade, es preciso remontarse a los últimos años del siglo XIx. La agricultura francesa habia sido literalmente puesta en «incubadora» por el proteccionismo aduanero, el arancel de 1892, la política de los «oportunistas» y de Jules Meline. Esta política, que puso a la agricultura francesa al abrigo de las corrientes de aire, quiero decir de toda concurrencia sobre el mercado nacional, ha producido los efectos que se podía esperar: en un medio tradicionalista y oportunista, preservado por otra parte de toda concurrencia, la agricultura francesa está esclerotizada en lo que no se atreve a llevar métodos, sino más bien rutinas, llevando un buen medio siglo de retraso. Ahora bien, se ha comprobado que gracias a diversos factores, la juventud campesina ha tomado conciencia, después de una quincena de años, de lo absurdo de tal estancamiento y que tiene (en ciertos casos bajo la influencia de un joven clero dinámico y organizaciones católicas de juventud agrícola) montado su tradicional individualismo y que se ha agrupado, desde luego, para mejorar sus métodos culturales; y este cambio notable tiene un sentido muy acertado, pues la agricultura francesa, que ha progresado en diez años más que en un siglo, se encuentra ante una situación de superproducción, la. demanda de productos agrícolas y particularmente productos alimenticios, siendo mucho menos elástica que la oferta. Los agricultores de las generaciones nuevas, habiendo tomado conciencia de esta situación, no la aceptan, $o$ al menos no aceptan sus consecuencias, y estamos asistiendo a un movimiento sin precedente en favor de la reestructuración de la empresa agrícola, de la busca de su dimensión optima. El movimiento que ha venido a parar en leyes sucesivas de orientación agrícola y en la institución SAFER no tiene, sin duda, más que una llamada limitada con relación a otros fenómenos económicos o sociales de nuestra época, pero es, sin embargo, uno de los más notables, desde el punto de vista sociológico, porque es uno de los más inesperados, $y$, sin duda, no ha desarrollado todavia todas sus consecuencias. En todo caso señala desde el momento presente. no solamente el nacimiento de una conciencia de la clase campesina, completamente distinta de la conciencia de clase obrera, sino también una extraordinaria capacidad de ruptura con las tradiciones seculares de individualismo y de resistencia al progreso técnico». 
que amenazan con aplastar el desarrollo de las más deseables y óptimas reformas (25). La Administración forestal, la Extensión agraria $\mathrm{y}$, sobre todo, la Ordenación rural son los protagonistas definitivos de estas futuras tareas.

\section{CONCLUSIONES}

Los bienes comunales se apoyan en una fórmula de explotación comunitaria realizada por los vecinos de los Municipios y de otros grupos de población. Esta fórmula, que hunde sus raíces en lo más profundo de la Historia, responde a éxigencias de validez uriversal y que se perpetúan en la hora presente. Ahora bien, su regulación jurídica ha quedado desfasada, perjudicando su espontánea y natural vitalidad e impidiendo su adaptación a las actuales circunstancias socio-económicas.

En efecto, la legalidad vigente pone su énfasis casi exclusivo en la explotación colectiva o comunal de estos bienes de forma directa que se traduce en la realización de aprovechamientos inmediatos. Ello era lógico en las épocas históricas que favorecieron su creación y en las que predominaba una economía vecinal, autárquica, y en las que las pequeñas colectividades rurales deficientemente interrelacionadas habrían de proveer sustancialmente a la autosatisfacción de las necesidades de sus habitantes. Estos contaban para ello con las tierras que cultivaban aisladamente y con los montes propiedad del común de donde extraían materias primas indispensables para su economía doméstica, leñas y maderas, $y$ en los que pastaban los reducidos ganados de los vecindarios. Ahora bien, en estos momentos estamos ante una economía de mercado medida definitivamente por valores monetarios. Ha sur-

(25) Vid. las medidas en este sentido aconsejadas por SIGUÁN, op. cit., páginas 149 y siguientes. Aun reconociendo que todo tipo de centralización es desintegrador, en el Informe scciológico de la situación social en España, de FOESSA, se admite iguaimente que si «se deja a las pequeñas comunidades que resuelvan los problemas por sí mismas, las circunstancias estructurales que hemos señalado (excesiva dispersión de la población, falta de bienes comunales, etc.) hace que el problema sea difícilmente solucionable; vid. volumen IV de la redacción provisional. Madrid, junio, 1966, página 773 . 
gido además con un ímpetu arrollador un fenómeno de organización económica: la empresa. La regulación de los bienes comunales debe, pues, acompasarse a estos nuevos condicionantes.

No se trata de propugnar su desnaturalización, sino, por el contrario, acomodar su intrínseca sustancia colectiva a las exigencias contemporáneas. Por ello se sugiere que la explotación productiva se haga hoy no fragmentaria y antieconómicamente, sino de acuerdo con fórmulas sensibilizadas a los caracteres de la explotación agrícola moderna. En este sentido parece que la cooperativa constituye el cauce idóneo y la respuesta actual a las esencias a que los bienes comunales responden. El futuro del campo español es en buena parte colectivo y en este futuro los bienes comunales pueden desempeñar un importante papel impulsando el lanzamiento de empresas agrarias comunitarias que vendrían así respaldadas en una sólida base tradicional y en un sustratum económico que facilitaría, con el apoyo de los Ayuntamientos, el proceso de capitalización imprescindible.

Con ello se pretende además revitalizar el Municipio rural acercándole a sus vecindarios y evitando que sea una mera solución administrativa muchas veces sin contenido por falta de materia que administrar, incorporándole a las preocupaciones básicas de los habitantes del término que en el campo, como es sabido, son sustancialmente de carácter agrícola.

La renovación, pues, tendría un carácter más profundo que la mera revisión de la actual legislación de los bienes comunales. Es el futuro del Municipio rural el que entra en juego y que conjugando la fórmula Ayuntamiento, cooperativa y bien comunal, puede aparecérsenos más esperanzador. Algunos brotes, bien que episódicos, se están produciendo ya en este sentido; debemos, pues, explorar estas posibilidades no como solución mágica, pero sí como un valioso apoyo en un terreno en el que está ahora planteada seriamente la lucha del desarrollo y en el que, por tanto, todas las ayudas son pocas. Aunque la cifra que hoy se da de la extensión de estos bienes, ocho millones de hectáreas, sea quizá excesiva, no puede desconocerse que la potenciación de la propiedad comunal supondrá un importante estímulo para el impulso del progreso del campo español. Puede posiblemente resultar pa- 
radójico el que en algunos casos los campesinos abandonen dolorosamente sus lugares natales sin haber agotado aún las posibilidades de rendimiento económico de sus campos.

Otro problema también vinculado con los bienes comunales es el del reconocimiento legal de la existencia de algunas comunidades no reconocidas como Ayuntamientos, pero que son efectivamente titulares de bienes, sobre todo en el noroeste de España, y que encuentran así dificultades adicionales para su explotación. No se defiende el acentuamiento de la dispersión administrativa, sino la armónica integración en el seno de los Ayuntamientos de esos pueblos, parroquias, lugares, ignorados oficialmente pero que tienen una existencia colectiva propia e indudable.

Por último debe señalarse que la reforma que aquí se pretende no podrá llegar a buen fin sin reanimar el espíritu colectivo de nuestros pueblos largamente constreñido por las preocupaciones individualistas de la legislación ilustrada y decimonónica. Para esta tarea no bastará con variar las normas administrativas, es necesario llegar al pueblo y dialogar con él; es aquí donde el concurso de los esforzados y jóvenes equipos del Ministerio de Agricultura habrán de jugar un insustituible papel haciendo honor a la confianza que los administrativistas $y$, sobre todo, los propios campesinos han en ellos ya depositado. 